\title{
Centralized Admission System for Advanced Level Private Schools: Case of Kilimanjaro Region, Tanzania
}

\author{
Mwapashua H. Fujo ${ }^{1}$, Mussa Ally Dida ${ }^{1 *}$ \\ ${ }_{1}^{1}$ The Nelson Mandela African Institute of science and Technology (NM-AIST), P.O.Box 447, Arusha, TANZANIA
}

*Corresponding Author: mussa.ally@nm-aist.ac.tz

Citation: Fujo, M. H. and Dida, M. A. (2019). Centralized Admission System for Advanced Level Private Schools: Case of Kilimanjaro Region, Tanzania. Journal of Information Systems Engineering \& Management, 4(1), em0088. https://doi.org/10.29333/jisem/5743

Published: March 24, 2019

\begin{abstract}
Globally, it is desirable to have fair and transparent student admissions into both public and private universities, colleges and schools. A case in point, in Tanzania 35\% of students enrolled each year in higher level learning institutions and technical education are from Advanced Level (A-level) private schools. Of concern is that, this paper confirms and quantify that $93.5 \%$ of admissions into A-level schools were performed on paper based. Such admissions were characterized by multiple admissions, being costly, inconsistency, inaccuracy, and difficulties in following admission procedures. On the other hand, existing manual admission systems were considered unfair and not transparent. To mitigate these challenges a centralized web-based solution named Tanzania Central Processing Admission System (TCPAS) has been conceptualized to resolve the identified admission challenges. This paper presents on an ongoing research work aimed to address the challenges facing the current admission procedures of A-Level private schools in Tanzania. The proposed TCPAS is designed to be a web-mobile solution. The TCPAS tool is intended to reduce admission costs by reducing turnaround time for entire admission processes; encourage the use of paperless admission; control forgery over entry qualifications (certificates) during the admission process; has a centralized data handling capability; saves admission vacancies; and reach many geographically scattered applicants. Moreover, questionnaires were used to gather requirements from 150 respondents from the case study (Kilimanjaro region).
\end{abstract}

Keywords: Central Admission System (CAS), Web Portal, A-Level Private Schools, Admission System, National Examinations Council of Tanzania (NECTA), Certificate of Secondary Education Examination (CSEE)

\section{INTRODUCTION}

Throughout the world, millions of students apply for admission to graduate schools, colleges or universities during the last year of their pre-college education. Normally the admission approaches differ from country to country (Hafalir and Kübler, 2014). For instance, in Nigeria, the processes for admission into tertiary institutions are decentralized in the sense that each university or college has an equal chance to decide on their admission independently. Such decentralization is known to cause problems in terms of setting standards, uniformity in the admission processes and multiple admissions. As a result, it is possible for one candidate to receive offers of admission from more than one institution or college. This has been proved to be costly in terms of time and money. While some applicants will not be able to apply to many colleges, also others would be admitted to more than one college and abandon some of the vacancies. Therefore, this makes the application procedures, even less fair and less considerate (Judith and Asein, 2007). 
In contrast, in 2010 to 2011 the government of Tanzania directed higher and technical education institutions to enroll students through a Centralized Admission System (CAS), which was under the supervision of the National Council for Technical Education (NACTE) in collaboration with the Tanzania Commission for Universities (TCU). Unfortunately, both of these two boards were focused only on the tertiary education level (TCU, 2014). However, in 2017 the government of Tanzania revoked the admission processes through TCU. Currently, institutions can process the admissions on their own. TCU and NACTE only foresee admission processes and set the criteria for enrolment to different programs. Once candidates admitted, institutions were required to upload the selected candidates into the system for TCU to approve. Therefore, Tanzania has gone back to the previous system of admission, which is very costly. However, the previous decentralized/institutionalized admission system encourages institutions to work hard for good reputation (TCU, 2017).

Apparently, it has been reported that over $35 \%$ of students enrolled each year in higher level learning and technical education in Tanzania are from A-Level private schools. And the number of A-Level private schools is increasing by $2 \%$, each year (Mangindaan et al., 2013). However, the enrolment of students in A-Level private schools is done on paper based which is difficult to perform, less accurate and very slow to complete the overall admission process (Ministry of Education, 2016).

This paper presents on an ongoing research work aimed to address the challenges facing the current admission procedures of A-Level private schools in Tanzania. The proposed solution is a software-based Centralized Admission System named Tanzania Central Processing Admission System (TCPAS) that has the capabilities to control and manage the performance and enrolment of students in A-Level private schools. The rest of the paper is organized as follows: Section 2 presents a review of related studies in the literature review. Section 3 concentrates on a set of principles, tools, and techniques that have guided the reported study. Section 4 presents the discussion of results as revealed from the analysis of survey data in this study. Section 5 has the conclusion and future work.

\section{RELATED WORKS}

\section{Students' Admission Systems in Developed Countries}

Globally, there are different admission systems that evaluate the applicant's quality before being admitted into schools or colleges and control the widening access to higher education. But, there were are unsolved difficulties like, how to save admission vacancies (applicant cannot be approved to join more than one school or college at once), centralized data handling capability, how to reduce the cost of admission processes (through reduction of turnaround time for entire admissions process), how to reach many geographical scattered applicants, how to encourage use of paperless admission, and how to ensure control over forgery of entry certificates during applications (Mahundu, 2016). Such admission systems that face named challenges include University College Admission System in China (CUCAS). Joint University Programmed Admission System in Hong Kong (JUPAS). Universities and Colleges Admission Service (UCAS) in the United Kingdom. And the Common Application in the United States of America (Zhang, 2009).

For instance, the CUCAS is one among the unique college admission system in the world due to its functionality. It consists of two stages. Stage one is a standard exam called the National College Entrance Examination, and stage two is the recruitment procedure which starts soon after exam results are released. Such admission procedure has caused students to invest a lot of time and effort to prepare for such exams. Conversely, this admission procedure is very difficult and frustrating (Zhang, 2009). For this reason, it has been agreed that the answer to this challenge is to have automated Centralized Admission System (CAS) (Mahundu, 2016).

\section{Students' Admission Systems in Developing Countries}

In developing countries, the introduction of a CAS is one of the greatest initiatives for monitoring and controlling quality for admission into tertiary education. Additionally, it is very important to provide a transparent and fair admission procedure for candidates aspiring to join Higher Education Institutions (HEIs). Some drawbacks like scarce resources, underdevelopment, gender inequality and the quest for advancement in science and technology, has led to the need to use a fair method of selection for admission, to ensure an equitable distribution of the available spaces in Ordinary, Advanced and Tertiary institutions (Bailey, 2014).

For instance, admission into public universities in Kenya is done by the government exclusively through a body popularly known as the Joint Admissions Board (JAB). This board sits periodically to select qualified students whom it assigns to different disciplines and to different public universities and university colleges. However, in such a process, there is a lack of fairness and transparency during the admission processes (Wabwoba and Mwakondo, 2011).

Similarly, in Tanzania, TCU and NACTE as education regulatory boards jointly established a CAS that become operational in 2010 (TCU, 2014). The TCU and NACTE admission systems were to assist applicants to deploy 
and retrieve their applications through a web-mobile application (TCU, 2014). However, it remained a challenge to have TCU provide a fair and transparent admission process that provides equal opportunity for all candidates regardless of their background and gain admission to a course appropriate to their proficiency and ambitions. Consequently, the government of Tanzania decided that there is no easy way to improve the current admission procedure than to invent a new software tool. This discussion left institutions with the mandate to process the admissions on their own. Instead, TCU and NACTE now only guide the admission processes as well as monitor the criteria for enrolment in various colleges and universities (TCU, 2017).

Parallel to the TCU/NACTE system, applications for admissions to Ordinary Level (O-Level) and A-Level secondary (pre-college) education in Tanzania is processed by two systems: A Central Regulatory Board that is governed by the government for public schools and direct applications for private schools. The Central Regulatory Board provides forms for O-Level students to select the schools of their choice for their A-Level studies. However, the only listed schools in the forms are public schools (Mangindaan et al., 2013). Private schools' applicants have to identify a school and physically collect the application forms themselves. Then, they were required to take the forms back to the specific school's administration. After processing the application, the respective school sends feedback of acceptance or rejection back to the applicant. This makes the application procedures very tiresome and costly. Additionally, less awareness of the existence of private schools and cost to a school are the major drawbacks of the current admission procedures (Kapinga, 2016). Therefore, the study proposes development of centralized web-mobile solution to enhance the performance of admission processes and resolve admission challenges facing the current admission procedures of A-Level private schools in Tanzania.

\section{METHODOLOGY}

\section{Case Study}

Kilimanjaro region one of the 31 administrative regions of Tanzania, was selected as a study area for the reported study. Kilimanjaro has a population of 1,640,087 (National Bureau of Standard, 2013). The region is located on the slopes of a temporarily inactive volcano of Mount Kilimanjaro, the biggest mountain in Africa. Also, it is bordered by Tanga Region in the south, with Kenya in the east and north, with Arusha Region in the west, and to the southwest of the Manyara Region (UNDP, 2014). The reason for selecting the Kilimanjaro Region as a case study is due to colonialism impacts, demographic factors and religious activities as causal factors resulting in having more A-Level private schools (pre-college schools) compared to other regions in Tanzania. Likewise, historically, $68 \%$ of Kilimanjaro parents strive for the best learning environment for their children. Moreover, most of the private schools have proven to have the best quality A-Level education (Ministry of Education, 2016).

\section{Sampling Strategy}

As revealed from the reported literature, it was considered necessary to confirm and quantify the unsolved admission challenges and its impacts on current procedures for admission of A-Level private schools in Tanzania. To achieve that, during the month of February 2018, the authors made every effort to reach all relevant users of the current admission systems of A-level private schools in Tanzania; namely: parents, pre-college students and school staffs, to ensure that credible data are collected for the success of the study. However, data were collected from 150 respondents through the use of questionnaire method and all entries retrieved as correctly filled were subsequently used in the analysis.

Nevertheless, it is recommended that, in order to determine the margin of error in the number of sample size range in between 150 to 250, the sample entries should be divided into three units (Mangindaan et al., 2013). Thus, the 150 sample entries were clustered into three groups of system users. In the first group, a sample of households was considered, in which 25 houses which were expected to have at least one applicant were selected. Second group involved a sample of school staffs: in which 25 admissions officers were selected. And in the last group, a sample of students was considered; in which 100 pre-college students were selected randomly from the study sample in order to reach the targeted group. The motive of getting 100 pre-college students rather than 50 entries, is because, a confidence level of pre-college students confirmed to be close to less to $95 \%$. Therefore, so as to cut back the possibility of creating a wrong conclusion regarding the population from the sample estimate, this study most well-liked to double the present entries, that's 50 to 100 entries. Thereafter the remained sample was divided equally to both school admission officers and households by 25 entries for every cluster. These three groups of samples were used to harmonize the chance of selection among the system users and giving them equal opportunity to participate in the study. 
Table 1. Present applicants' residences in relation to the school location in Kilimanjaro Region

\begin{tabular}{llcc}
\hline & & Frequency & \multicolumn{2}{c}{ Percentage } \\
\hline \multirow{3}{*}{ Variables } & Applicants from Kilimanjaro Region & 95 & 63 \\
\cline { 2 - 4 } & Applicants from outside Kilimanjaro Regions & 55 & 37 \\
\cline { 2 - 5 } & Total & $\mathbf{1 5 0}$ & $\mathbf{1 0 0}$ \\
\hline
\end{tabular}

\section{Data Collection Methods}

Questionnaires were used to collect data from the parents who were sending their children to A-Level private schools than public schools. Also, used for selected A-Level students who have already interacted with current admission procedures and gained admissions in A-level private schools. In the third group, school admission officers who demonstrated to be familiar with all procedures and methods of processing students' admission requests for A-Level private schools were consulted and interviewed. A questionnaire was selected for this research because it is a reliable and quick method to gather information from multiple respondents in an efficient and timely manner. Again, this study was no exception and questionnaires were a quick and effective approach for the researcher to reach multiple respondents at interval within several weeks.

\section{Methods for Data Analysis}

The distributed survey questionnaires had both hard-copy, and soft-copy structured questions which were administered by using the Open Data Kit (ODK) software. Thereafter, the collected statistical data (both quantitative and qualitative data) were analyzed with the intention of; firstly, to identify the applicant's residence in relation to the school location, to measure the delay caused by manual admission procedures, to assess availability and applicability of regulatory board for current admission procedures, and to know how current admission procedures of A-Level private schools are handled, to measure the level of fairness of current admission procedures of A-Level private schools, to measure delivering candidates' expectation rate for A-Level private schools, and finally to assess the current methods for admission processing of A-Level private schools. In these cases, SPSS software as statistical package was used for analyses, because, SPSS provides the simplest and standard virtualization of tables and charts (pie charts and histogram) compared to alternative statistical packages like R, Excel and SAS. For instance, in Excel each and every calculation needs manually entering a formula, leaving ample room for error. Parallel to that, R and SAS it is tricky to learn, depending on programming background.

\section{RESULTS AND DISCUSSION}

This section discusses the challenges of the current manual admission systems as revealed from the analysis of survey data collected by using questionnaires, and its consequences on the current admission procedures of ALevel private schools in Tanzania.

\section{Does the Present Manual Admission Systems Reach the Candidates that are Scattered Geographically?}

Table 1 shows the survey results on applicants' residences. The results show that, about $37 \%$ of applicants in Kilimanjaro Region, Tanzania are from outside the region of Kilimanjaro, but the majority of them face challenges on awareness about the existence of A-Level private schools. Due to the fact that, most of the A-Level private schools in Kilimanjaro use regional media like Radio and TV (Example: Kilimanjaro-FM) for the advertisement, which in turn cost money, as well as an airtime slot for advertisement. This admission process is expensive for some of the schools. Furthermore, media adverts are not broadcasted countrywide, thus access to geographical scattered applicants remains to be a significant challenge.

\section{Do the Present Manual Admission Systems Guarantees Centralized Data Handling Capability?}

During the analysis of survey data, it was realized that the current procedures for admission into A-Level private schools is fully decentralized, which causes further delay in commencing new academic years and makes it hard for applicants to make final decisions for their studies (about where, when and which subjects they can fit in). Each school has its own rules and procedures to monitor and control their admission processes. Also, there is a lack of central board to set standards for admission of A-Level private schools. Consequently, the majority of A-Level private schools in Kilimanjaro region take a month or more than a month to process all admission requests per academic year. 


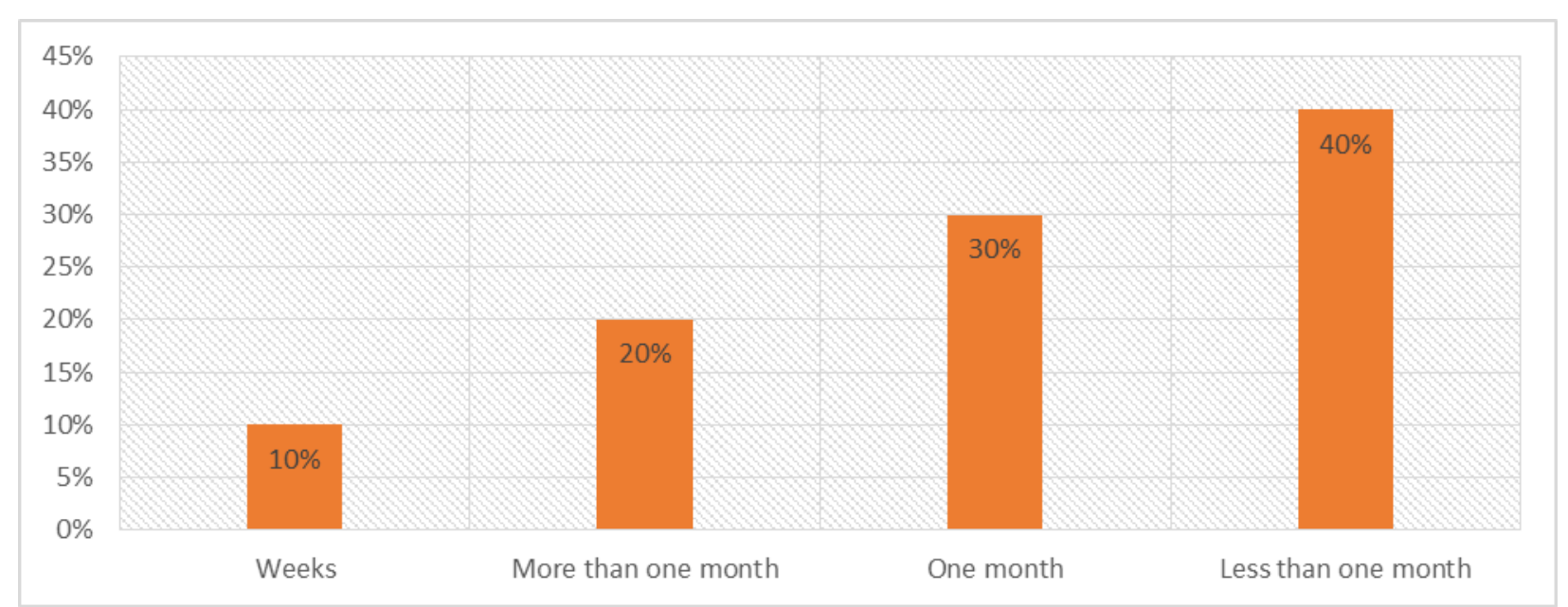

Figure 1. Present the delay caused by current manual admission procedures of A-Level private schools in Kilimanjaro Region, Tanzania

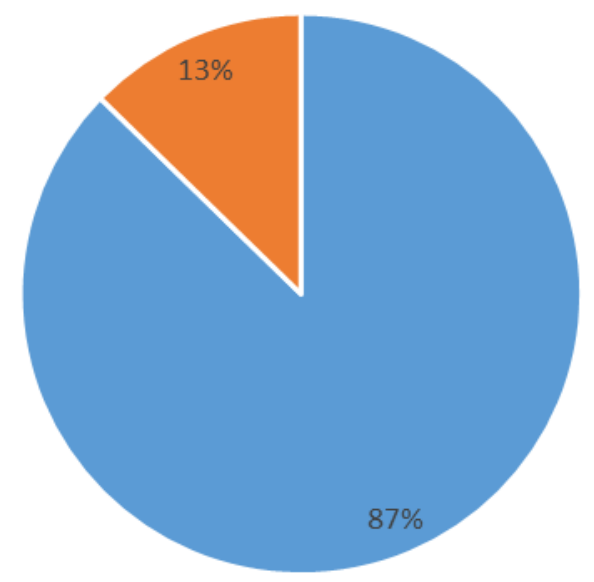

- A-Level private schools without regulatory boards

- A-Level private schools having regulatory boards

Figure 2. Present availability and applicability of regulatory board for current manual admission procedures of ALevel private schools in Kilimanjaro Region, Tanzania

\section{Do the Current Manual Admission Systems Ensure Management of Forgery Entry Certificates throughout the Application?}

Survey results in Figure 2 show that, $87 \%$ of A-Level private schools in Kilimanjaro region have no central regulatory board to guide and govern the entire admissions process, which leads to inconsistency and difficulties during verification of entry qualifications (certificates). Because of this, once the candidates admitted, schools were required to upload the selected candidates into the system for TCU and NACTE approval. As a result, while waiting for TCU and NACTE approval, most A-Level private schools in Kilimanjaro region were delayed in commencing new academic years. Moreover, only 13\% of A-Level private schools in Kilimanjaro region use their own boards as a shield to mask, control and maintain fairness and transparent admission processes.

\section{Does the Current Admission Procedures of A-Level Private Schools Costly?}

Survey results in Figure 3 confirm that, despite of the contribution of A-Level private schools to higher level learning and the existence of these two systems for admission in Tanzania (NACTE and TCU); still procedures for admission into A-Level private schools are handled on paper based (94\%), which consumes much time, up to 3 months and in the average costs of US $\$ 22$, for each applicant from different regions in Tanzania during the entire processes of admission. This makes the application procedures to be frustrating and costly. 


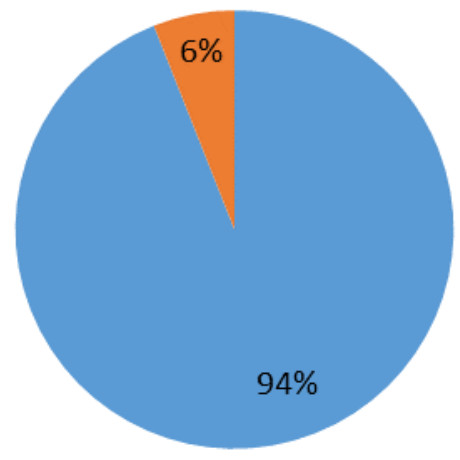

घdmission procedures handled manually $\quad$ admission procedures handled electronically

Figure 3. Shows how current manual admission procedures of A-Level private schools in Kilimanjaro Region, Tanzania are handled

Table 2. Present the level of fairness of current manual admission procedures of A-Level private schools in Kilimanjaro Region, Tanzania

\begin{tabular}{llcc}
\hline & & Frequency & Percentage \\
\hline \multirow{2}{*}{ Variables } & Response rate based on unfair admission & 103 & 69 \\
\cline { 2 - 4 } & Response rate based on fair admission & 47 & 31 \\
\cline { 2 - 4 } & Total & $\mathbf{1 5 0}$ & $\mathbf{1 0 0}$ \\
\hline
\end{tabular}

Table 3. Present the delivering candidates' expectation rate for A-Level private schools in Kilimanjaro

Region, Tanzania

\begin{tabular}{lcc}
\hline Variables & Frequency & Percentage \\
\hline A-level private schools that deliver a number of candidates that are below their expectations & 117 & 78 \\
\hline A-level private schools that deliver a number of candidates that are within/above their expectations & 33 & 22 \\
\hline Total & $\mathbf{1 5 0}$ & $\mathbf{1 0 0}$
\end{tabular}

\section{How is the Fairness of Current Admission Procedures of A-Level Private Schools?}

From the Survey results in Table 2, the study revealed that, $69 \%$ of respondents agreed that the current admission systems are unfair and not transparent, because there exist major challenges like gender inequity, scarce resources, underdevelopment, and the quest for advancement in science and technology and religious barriers in A-Level private schools in Kilimanjaro region. In this respect, there is no way than use a fair method of selection at the time of admission, to ensure an equitable distribution of the available vacancies during the time of admission processes.

\section{Does the Current Admission Procedures of A-Level Private Schools Handle Admission Vacancies?}

Survey results in Table 3 show that, in the absence of a centralized system to monitor and control admissions of A-Level private schools, one applicant physically collects forms from various schools and lodges multiple applications. In the sense that, it may lead one applicant to be admitted into more than one school, and eventually pick one vacancy and still abandon some of the vacancies from other schools. Consequently, this study shows that $78 \%$ of A-Level private schools in Kilimanjaro Region deliver a number of candidates that are below their expectations.

\section{Does the Present Admission Procedures of A-Level Private Schools Encourage the Use of Paperless} Admission?

Apparently, the survey results in Figure 4 show that $51 \%$ of admissions of students of A-Level private schools are done on paper based which is very slow, less accurate, difficult to complete as well as time and effort consuming. Although, 30\%, 16\% and 3\% of A-Level private schools in Kilimanjaro region, respectively, also use methods like postal office, phone calls, and electronic mail. These methods still are not effective and efficient to reduce the use of paper based admissions. For this reason, there is a need to have a tool to control and manage the use of paper to print admissions and enhance the enrolment of qualified students into A-Level private schools in Tanzania. 
Physically

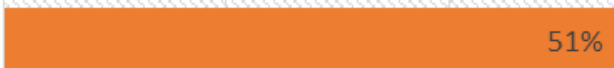

Phone calls

$16 \%$

Postal Office

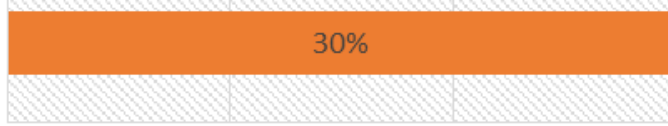

$0 \%$

$10 \%$

$20 \%$

$30 \%$

$40 \%$

$50 \%$

$60 \%$

Figure 4. Present the current methods for admission processing of A-Level private schools in Kilimanjaro Region in Tanzania

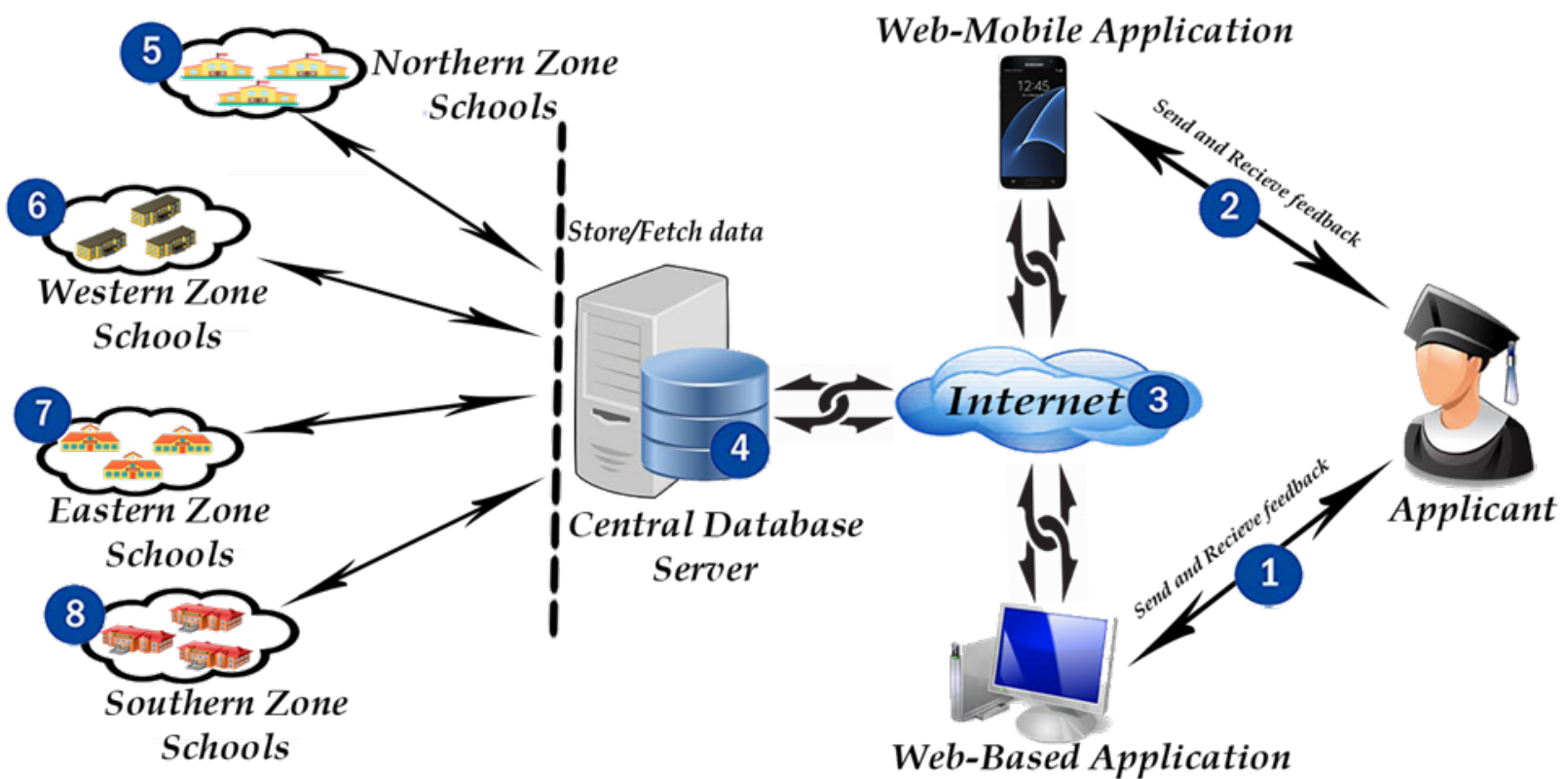

Figure 5. Present framework of the designed software tool (TCPAS)

\section{DESIGNED SOLUTION}

The designed TCPAS is going to be a client-server based system, which will consist of the following interfaces: user interface and server-side interface that are linked together via an internet connection. For this reason, initially an applicant will be able to send admission requests by either his/her computer or smart-phone through a webbased application, or web-mobile application (as shown in step 1 and 2 of Figure 5). Then in (step 3 to 4 ) all applicant requests will be stored within the centralized database server with the help of internet connection between the client and server-side. Then, the server will send these requests to several schools for processing (either in location 5, 6, 7 or 8), depending on school location or zone. After the schools receive the applicant queries, instantly will process it, store and send acknowledgement feedback of acceptance/rejection back to the centralized database server (step 4). Thereafter, the server will allocate these notifications of acceptance/rejection to the respective applicants through mobile phone messages, E-mail and applicant profile, through a web portal (as shown in step 3,2 and 1). Therefore, it is necessary to conclude that, the designed software solution uses bi-directional approaches, that means support two-way interaction (to-and-fro/forward-and-backward) approaches. 


\section{Requirements Specification of the Designed Software Solution (TCPAS)}

As far as this study is concerned below mentioned are the requirements extracted from the analysis of survey data as revealed in this study.

a) The designed software solution must provide a mechanism to reach to several candidates scattered geographically.

b) The designed software solution should handle the admission information in a centralized approach.

c) The designed software solution should provide means of controlling, monitoring and tracking forgery of entry qualifications throughout the admission process.

d) The designed software solution should diminish the cost of admission; mainly should make the admission cost affordable and acceptable to all users/applicants.

e) The designed software solution should manage multiple admissions.

f) The designed software solution should control and maintain fairness and transparency throughout the admission process.

g) The designed software solution should provide a means of handling and managing admission vacancies.

h) The designed software solution should promote on the use of paperless admission.

\section{Contributions of the Designed Software Solution (TCPAS)}

The designed TCPAS software tool (Web-mobile) will deploy a direct communication link to both A-Level private schools, and applicants scattered geographically across all regions in Tanzania via a web browser. Also, it will provide equitable access for applicants to send admission requests to schools through their computers and smartphones in their geographical position. This way the TCPAS will achieve the requirement of A-Level private schools reaching applicants scattered geographically.

Also, the designed application tool (TCPAS) will help to transfer data in a smooth way for all candidates and schools registered in the system; which handles the data in a centralized way. The details of each A-Level private school in Tanzania including school name, location or physical address, academic performance (its position in the national Exams), school services and school vacancies will be provided in a Web-portal interface of the TCPAS based on zones (Northern, Western, Eastern and Southern Zone in Tanzania). This way it makes it easier for applicants to locate and spot those schools and services offered by schools.

Nonetheless, in the designed software tool (TCPAS), printed or scanned copies of certificates will no longer be required during admission of A-Level private schools in Tanzania. Instead, candidates will only be required to provide the index number for their Certificates of Secondary Education Examination (CSEE). The verification will be done by the system automatically through an Application Programming Interface (API) to the NECTA database integrated within the TCPAS.

Additionally, the designed TCPAS software tool will enable applicants to pay US $\$ 2.6$ as an application fee, and capable of doing multiple admissions based on his/her choice at affordable prices. Alternatively, all payments will be made electronically through mobile (Tigo-Pesa, Mpesa, etc.) or banking financial services. International Telecommunication Union (ITU) recommends a monthly affordability of less than $5 \%$ of monthly income (UNOHRLLS, 2018). In the case of Tanzania, basic salary per month is US $\$ 78$. The $5 \%$ of this amount is approximately US $\$ 3.9$, which translates into US $\$ 0.13$ per day. It is considered that the admission processing fees per applicant should not exceed this amount (US\$3.9). Additionally, the designed system will provide weekly notifications in regards to admission progress. Thus, such application tool will make the entire admission procedures far easier and less costly.

Furthermore, the designed TCPAS software tool will use bi-directional (to and fro) approaches in the sense that: firstly, an applicant will be allowed to perform multiple admissions requests; and later on may receive multiple acknowledgements from more than one school. And finally, the applicant will be permitted to acknowledge and send acceptance only to one school, thereby leaving vacancies to others. By doing so, TCPAS will meet the requirement of controlling and managing multiple admissions and saving admission vacancies for A-Level private schools in Tanzania.

Finally, with the designed TCPAS software tool, applicants will no longer need to collect and fill physical forms. Instead, they will perform the applications through a web portal and answer all the required queries, at the same time it will send notifications to applicants using mobile phone messages and Electronic Mail for all computers and mobile users. Consequently, it will control and manage the use of paper to print admissions; that is a paperless admission procedure.

\section{Limitations of the Designed Software Solution (TCPAS)}

Security concerns: in a developing country like Tanzania where quest for advancement in science and technology still becomes a challenge. Thus, it makes easier for application systems to be breached and users' information to be manipulated. A case in point of centralized admission systems, failures of the server due to an 
attack may disrupt the entire system for admission and cost universities, colleges or schools in terms of confidentiality, integrity and availability of applicants' information.

Performance concerns: In any centralized systems all users' information is handled in a centralized way. Thus, access to resources available in a centralized server is very competitive. For this reason, without an alternative Domain Name System (DNS) and using a cloud technology, unintentional system failures or server crashes will become major drawbacks.

\section{CONCLUSION AND FUTURE WORK}

Nevertheless, it is revealed that, 94\% of admissions into A-Level private schools in Tanzania are currently decentralized and $51 \%$ are handled on paper based. As a result, applicants have to identify the schools, physically collect application forms and fill the forms manually. In the process, often applicants get confused while filling the application forms and face difficulties in choosing where to pursue their A-Level studies. The newly designed admission system (TCPAS) will have the capability to reduce the stress of applicants while filling the application forms. In one click, the TCPAS system will provide possible A-Level private schools and subjects an applicant can get admissions. Furthermore, using the new CAS system, probably applicants will get admission in the first round and if not, the system will offer the second round. Moreover, admission cost in terms of time and money will be reduced.

The future work will involve full development and implementation of the proposed software solution (TCPAS) which will involve the use of Hyper Text Makeup Language (HTML), Cascading Style Sheets (CSS), Hypertext Preprocessor (PHP), JavaScript and MySQL database. Parallel to that, the MD5 encryption algorithm will be used, because MD5 is compatible with MySQL and use a hash function to produce a 128-bit hash value of securities of critical users' information; mainly password. Thereafter, the designed solution will undergoes unit testing, integration testing, system testing and acceptance testing so as to evaluate the system in compliance with the specified requirements.

Lastly, despite of the actual fact that, this study focusing on and attempting to address the challenges facing the current manual admission procedures of A-Level private schools in Tanzania. But still this study leaves an ample room for others to contribute their technological innovation in a pre-college education in Tanzania, by adding another module in this designed software solution (TCPAS) which will enhance and facilitate in the area of monitoring and managing academic progress for both public and private schools.

\section{REFERENCES}

Bailey, T. (2014). The role and functions of higher education councils and commissions in Africa: A case study of the Tanzania Commission for Universities.

Hafalir, I. E. and Kübler, D. (2014). College Admissions with Entrance Exams : Centralized versus Decentralized *, $1-46$.

Judith, B. and Asein, E. (2007). Joint Admissions and Matriculation Board.

Kapinga, O. (2016). Assessment of School Facilities and Resources in the Context of Fee Free Basic Education in Tanzania, 1-11.

Mahundu, F. G. (2016). e-Governance: A Case Study of the Central Admission System in Tanzania. Electronic Journal of Information Systems in Developing Countries, 76(6), 1-11. https://doi.org/10.1002/j.16814835.2016.tb00557.x

Mangindaan, M. C., Elley, W. B., Medicine, T. C., OECD, Paper, P., Stacey, K. ... Notodiputro, K. A. (2013). Tanzania The Tanzanian education system described and system. Far Eastern Survey, 33(4), 1-16. https:// doi.org/10.1016/0145-9228(79)90001-3

Ministry of Education. (2016). Annual Education Statistics 2014.

National Bureau of Standard. (2017). 2012 Population and Housing Census Population Distribution by Administrative areas. NBS Ministry of Finance, 177, 180.

TCU. (2014). Tanzania Commission for Universities: Revised Admissions Guidebook for Higher Education Institutions in Tanzania, 246. https://doi.org/10.1017/CBO9781107415324.004

TCU. (2017). Tanzania Commission for Universities Undergraduate Admission Guidebook for Higher Education Institutions in Tanzania for Applicants with Form Six and RPL Qualifications.

UN-OHRLLS. (2018). Achieving universal and affordable Internet in the least developed countries. Retrieved from http:/ / unohrlls.org/custom-content/uploads/2018/01/D-LDC-ICTLDC-2018-PDF-E.pdf

UNDP. (2014). United Nations Development Program Country: Tanzania Project Title: Reducing Land Degradation on the Highlands of Kilimanjaro Region. United Nations Development Program, 1-67. 
Wabwoba, F. and Mwakondo, F. M. (2011). Students selection for university course admission at the joint admissions board (Kenya) using trained neural networks. Journal of Information Technology Education, 10(1), 333 347. https:// doi.org/10.28945/1529

Zhang, H. (2009). An Analysis of the Chinese College Admission System. 